\title{
Abscisic Acid Negatively Modulates Heat Tolerance in Rolled Leaf Rice by Increasing Leaf Temperature and Regulating Energy Homeostasis
}

Guangyan $\mathrm{Li}^{1,2 \dagger}$, Caixia Zhang ${ }^{3 \dagger}$, Guangheng Zhang ${ }^{1}$, Weimeng Fu', Baohua Feng ${ }^{1}$, Tingting Chen ${ }^{1}$, Shaobing Peng', Longxing Tao ${ }^{1 *}$ and Guanfu Fu ${ }^{1 *}$

\begin{abstract}
Background: Abscisic acid (ABA) acts as a signaling hormone in plants against abiotic stress, but its function in energy homeostasis under heat stress is unclear.

Results: Two rice genotypes, Nipponbare (wild-type, WT) with flat leaves and its mutant high temperature susceptibility (hts) plant with semi-rolled leaves, were subjected to heat stress. We found significantly higher tissue temperature, respiration rate, and $\mathrm{ABA}$ and $\mathrm{H}_{2} \mathrm{O}_{2}$ contents in leaves as well as a lower transpiration rate and stomatal conductance in hts than WT plants. Additionally, increased expression of HSP71.1 and HSP24.1 as well as greater increases in carbohydrate content, ATP, NAD (H), and dry matter weight, were detected in WT than hts plants under heat stress. More importantly, exogenous ABA significantly decreased heat tolerance of hts plants, but clearly enhanced heat resistance of WT plants. The increases in carbohydrates, ATP, NAD (H), and heat shock proteins in WT plants were enhanced by ABA under heat stress, whereas these increases were reduced in hts plants.

Conclusion: It was concluded that ABA is a negative regulator of heat tolerance in hts plants with semi-rolled leaves by modulating energy homeostasis.
\end{abstract}

Keywords: Oryza sativa L., Rolled leaf, Heat stress, Abscisic acid, Tissue temperature, Energy homeostasis

\section{Background}

Abscisic acid (ABA) is an important phytohormone controlling many developmental and physiological processes under natural and stressed conditions (Verslues and Zhu 2007; Huang et al. 2017). ABA accumulates in the developing embryo where it regulates seed development, seed maturation, and seed dormancy (Verslues and Zhu 2007). It also acts as a signaling molecule to defend against biotic stress including pathogen infection

\footnotetext{
* Correspondence: taolongxing@caas.cn; fugf1981@sina.com

†Guangyan Li and Caixia Zhang contributed equally to this work.

'National Key Laboratory of Rice Biology, China National Rice Research Institute, Hangzhou 310006, Zhejiang, China

Full list of author information is available at the end of the article
}

(Mittler and Blumwald 2015; Kang et al. 2017). Under drought stress, ABA accumulates to induce closing of leaf stomata to reduce water loss from plants (Guajardo et al. 2016), and enhances antioxidant capacity, heat shock proteins (HSPs), the sugar response, and accumulation processes for plants to tolerate desiccation (Guajardo et al. 2016; Yao et al. 2018; Jahan et al. 2019). Expression of the CBF/DREB1 transcription factors and cold-hardiness increase in grapevine dormant buds in response to ABA when the plants are subjected to cold stress (Rubio et al. 2018; Albertos et al. 2019). Additionally, ABA also functions in the heat stress response in plants, but the underlying mechanism remains unclear
Springer Open (c) The Author(s). 2020 Open Access This article is licensed under a Creative Commons Attribution 4.0 International License, which permits use, sharing, adaptation, distribution and reproduction in any medium or format, as long as you give appropriate credit to the original author(s) and the source, provide a link to the Creative Commons licence, and indicate if changes were made. The images or other third party material in this article are included in the article's Creative Commons licence, unless indicated otherwise in a credit line to the material. If material is not included in the article's Creative Commons licence and your intended use is not permitted by statutory regulation or exceeds the permitted use, you will need to obtain permission directly from the copyright holder. To view a copy of this licence, visit http://creativecommons.org/licenses/by/4.0/. 
(Suzuki et al. 2016; Zandalinas et al. 2016; Zhang et al. 2017).

Heat stress is defined as a rise in temperature beyond a critical threshold or period of time that can cause irreversible damage (Wahid et al. 2007; Zandalinas et al. 2018; Sehgal et al. 2019). Thermolabile proteins can be inactivated, reactive oxygen species (ROS) accumulate, and programmed cell death is induced in plants during this process (Grover et al. 2013; Liu et al. 2016; Zhang et al. 2016). Such stressors occurring during the reproductive stage significantly decrease grain yield (Feng et al. 2018; Zhang et al. 2018). It has been reported that ABA enhances heat tolerance in plants by increasing $\mathrm{H}_{2} \mathrm{O}_{2}$ levels to induce antioxidant capacity and HSPs ( $\mathrm{Li}$ et al. 2014; Islam et al. 2019). Additionally, ABA accumulates to enhance ascorbate peroxidase 1 and multiprotein bridging factor 1 activities to protect against heat damage in plants (Zandalinas et al. 2016). In contrast, a decrease in endogenous ABA level has been detected in plants sprayed with an ABA biosynthesis inhibitor, which impairs heat tolerance (Ding et al. 2010; Kumar et al. 2012). Importantly, heat-induced damage is more severe in ABA-deficient mutants than in their parental cultivars (Wang et al. 2014; Wu et al. 2017). It is worth noting that most of the current stress research is focused on understanding the ABA signaling pathway in heat tolerance of plants, and very few studies have been conducted on energy homeostasis in plants under heat stress.

Maintaining energy homeostasis is a challenge for all living organisms, and an intimate relationship exists between energy availability and stress tolerance in plants (De Block and Van Lijsebettens 2011; Dröge-Laser and Weiste 2018). Plant growth and development are inhibited or plants die if the extreme stress lasts until an energy threshold is reached at which time the damage caused by the stress can no longer be repaired (BaenaGonzález and Sheen 2008). Unfortunately, the enhancing HSPs and antioxidant capacity is a high energy consumption process in plants under stress (Flaherty et al. 1990; Grenert et al. 1997; Zhu 2016). Therefore, the accumulation of HSPs and enhancement of antioxidant capacity induced by ABA under heat stress might be related with its ability to maintain energy homeostasis or enhance energy-use efficiency (De Block and Van Lijsebettens 2011). This hypothesis was confirmed by the results of Islam et al. (2019), who reported that ABA enhances sucrose transport and metabolism to prevent depletion of ATP and maintain energy homeostasis in rice spikelets, and thus heat resistance.

However, negative modulation of ABA has also been detected in plants responding to abiotic or biotic stress. ABA increases susceptibility to a plant virus by modulating the rice-RBSDV interaction, suppressing the jasmonate pathway, and regulating ROS levels (Xie et al. 2018). When plants are exposed to heat stress, $10 \mu \mathrm{mol} \cdot \mathrm{L}^{-1} \mathrm{ABA}$ greatly enhances heat tolerance, while tolerance was reversed in the $100 \mu \mathrm{mol} \cdot \mathrm{L}^{-1} \mathrm{ABA}$ treatment (Robertson et al. 1994; Gong et al. 1998; Li et al. 2014). Interestingly, rice plants sprayed with $100 \mu \mathrm{mol} \cdot \mathrm{L}^{-1} \mathrm{ABA}$ attain higher pollen viability under heat stress at the pollen mother cell meiotic stage (Islam et al. 2019). These findings suggest that the negative effects of ABA shown in plants against stress are not only due to the high concentrations, but also the plant types, such as rolled leaf plants. Lower transpiration ability and higher leaf temperature are often found in rice plants with rolled leaves (unpublished data). This suggests that rolled leaf plants consume more energy due to a higher respiration rate under heat stress. In this case, more damage would be observed in rice plants with rolled leaves when sprayed with ABA under heat stress, possibly because $\mathrm{ABA}$ induces stomatal closure, resulting in lower net photosynthetic and transpiration rate but higher leaf temperatures (Islam et al. 2018). It has been inferred that more energy is required in rice plants sprayed with ABA. However, the relationship between $\mathrm{ABA}$ and energy homeostasis in rolled leaf plants has not been documented under heat stress.

In this study, more damage was found in mutant plants with semi-rolled leaves (high temperature susceptibility; hts) than its wild-type Nipponbare (WT) plants caused by heat stress. Higher leaf temperature and ABA content were observed in $h t s$ than WT plants under heat stress. Accordingly, greater increases in ATP and NAD $(\mathrm{H})$ contents were found in WT than hts plants under heat stress compared with their respective controls. Thus, we wondered whether ABA was negatively involved in heat acclimation by regulating energy homeostasis in rolled leaf plants as well as the heat damage exacerbated by exogenous ABA.

\section{Materials and Methods \\ Plant Materials and Growth Conditions}

This study was conducted at the experimental farm of the China National Rice Research Institute, Hangzhou, Zhejiang Province, China. Two rice genotypes, WT and its mutant hts, were selected for use in this study. The $h$ ts semi-rolled leaf mutant was isolated from the ethyl methane sulfonate-induced japonica rice Nipponbare mutant bank (Zhang et al. 2018). This mutant has been self-pollinated for more than nine generations, and the semi-rolled leaf phenotype has been stably expressed in the greenhouse and field. The rice seeds were directly sown in pots $(10 \mathrm{~cm}$ height and $10 \mathrm{~cm}$ diameter) in a plant growth chamber with an automatic temperature control system and controlled relative humidity until the five to six leaf stage. 


\section{The Response of Rice Plants to Different Temperature Stressors}

At the five to six leaf stage, WT and $h t s$ plants were subjected to different temperatures, such as $30^{\circ} \mathrm{C}, 35^{\circ} \mathrm{C}$, and $40^{\circ} \mathrm{C}$ for $72 \mathrm{~h}$, while the rice plants were only subjected to $45^{\circ} \mathrm{C}$ for $24 \mathrm{~h}$. During the stress period, the temperature was constant, and the relative humidity was $70 \%$ under natural sunlight conditions. The first fully expanded leaves were collected at the end of the heat stress period to determine maximum fluorescence quanta of PSII (Fv/Fm) and leaf ion leakage, as well as malondialdehyde (MDA) and chlorophyll contents.

\section{The WT and hts Plant Responses to Heat Stress}

According to the above results, the five to six leaf stage of WT and hts plants was subjected to heat stress at $40{ }^{\circ} \mathrm{C}$ for $72 \mathrm{~h}$. The control temperature was $30^{\circ} \mathrm{C}$. The temperatures were constant during the stress period, and relative humidity was $70 \%$ under natural sunlight conditions. Additionally, the first fully expanded rice leaves were collected about $4 \mathrm{~h}, 10 \mathrm{~h}$ (at night), $28 \mathrm{~h}, 34$ $\mathrm{h}$ (at night), $48 \mathrm{~h}$, and $72 \mathrm{~h}$ after the heat stress to determine the contents of carbohydrates, $\mathrm{ABA}, \mathrm{H}_{2} \mathrm{O}_{2}, \mathrm{NAD}$ $(\mathrm{H})$, and ATP as well as the relative expression levels of genes related to sucrose transport and metabolism, polyADP ribose polymerase (PARP) and HSPs. Additionally, leaf temperature, stomatal conductance, as well as transpiration and respiration rates were determined.

\section{Effect of ABA on Rice Plants under High Temperature Conditions}

According to the above results, ABA accelerated heat injury of rice plants with rolled leaves under heat stress. Therefore, different ABA concentrations, such as $1 \mu \mathrm{mol} \cdot \mathrm{L}^{-1}, 10 \mu \mathrm{mol} \cdot \mathrm{L}^{-1}$, and $100 \mu \mathrm{mol} \cdot \mathrm{L}^{-1}$, were used in this experiment. Chemicals containing $0.1 \%(\mathrm{v} / \mathrm{v})$ Tween20 as the surfactant were foliar applied at 9:00 a.m. at a volume of $10 \mathrm{~mL}$ per pot about $30 \mathrm{~min}$ before the heat stress. About $24 \mathrm{~h}$ later, leaf temperature during the day $(28 \mathrm{~h})$ and night $(34 \mathrm{~h})$, stomatal conductance, and transpiration rate were determined. The $\mathrm{Fv} / \mathrm{Fm}$ value of the leaves was determined when the heat stress ended. The samples of the first fully expanded leaves were collected to determine the content of carbohydrates, NAD (H), and ATP as well as the relative expression levels of genes related to sucrose transport and metabolism, PARP and HSPs.

\section{Measurement of Chlorophyll Content, Chlorophyll Fluorescence Parameters, and Gas Exchange}

Chlorophyll was extracted according to the method described by Sartory and Grobbelaar (1984). About $0.1 \mathrm{~g}$ of leaf sample was cut into pieces and immersed in $20 \mathrm{~mL}$ of $95 \%$ ethanol in the dark for $48 \mathrm{~h}$. Chlorophyll concentration was determined at $665 \mathrm{~nm}$ and $649 \mathrm{~nm}$ using a spectrophotometer (Lambda25; Perkin Elmer, Freemont, CA, USA). Chlorophyll $a$ and $b$ values were calculated with the following equations: $C_{a} \quad\left(\mu \mathrm{g} \cdot \mathrm{mL}^{-1}\right)=13.95 \times(\mathrm{A} 665)-$ $6.88 \times(\mathrm{A} 649), \mathrm{C}_{\mathrm{b}}\left(\mu \mathrm{g} \cdot \mathrm{mL}^{-1}\right)=24.96 \times(\mathrm{A} 649)-7.32 \times(\mathrm{A} 665)$.

Chlorophyll fluorescence was measured with a portable chlorophyll fluorescence spectrometer (PAM-2500 chlorophyll fluorescence system; Heinz Walz, Effeltrich, Germany). The Fv/Fm values were determined after a 30-min dark adaptation period.

Stomatal conductance and transpiration rates were analyzed using a Li-COR 6400 portable photosynthesis system (Li-COR Biosciences Inc., Lincoln, NE, USA) under the following conditions: photosynthetic photon flux density of $1200 \mu \mathrm{mol} \cdot \mathrm{m}^{-2} \cdot \mathrm{s}^{-1}$; ambient $\mathrm{CO}_{2}\left(400 \mu \mathrm{mol} \cdot \mathrm{mol}^{-1}\right) ; 6 \mathrm{~cm}^{2}$ leaf area; $500 \mu \mathrm{mol} \cdot \mathrm{s}^{-1}$ flow speed, and temperature according to the treatment.

The respiration rate of the leaves was also analyzed at night ( $2 \mathrm{~h}$ after dark) using the Li-COR 6400 portable photosynthesis system under the following conditions: photosynthetic photon flux density of $0 \mu \mathrm{mol} \cdot \mathrm{m}^{-2} \cdot \mathrm{s}^{-1}$; ambient $\mathrm{CO}_{2} \quad\left(400 \mu \mathrm{mol} \cdot \mathrm{mol}^{-1}\right) ; \quad 6 \mathrm{~cm}^{2}$ leaf area; $500 \mu \mathrm{mol} \cdot \mathrm{s}^{-1}$ flow speed, and temperature according to the treatment.

\section{Dry Matter Weight Measurement}

The rice plants were sampled to determine dry matter weight and its distribution at the end of the heat stress. The plants were divided into leaf and sheath-stems, and were dried at $85^{\circ} \mathrm{C}$ for $48 \mathrm{~h}$ and weighed.

\section{Carbohydrate Measurement}

According to the methods of DuBois et al. (1956) with some modifications, about $0.5 \mathrm{~g}$ of frozen leaves was extracted with deionized water. The concentration of starch was determined at $620 \mathrm{~nm}$ using a spectrophotometer. The extracting method for sucrose, glucose, and fructose was similar to that of soluble sugars. Sucrose, glucose, fructose and soluble sugar contents were determined by the methods of Zhang (1977) with some modifications. Total non-structural carbohydrate (NSC) content was considered the sum of the soluble sugar and starch contents.

\section{Thermal Imaging of Rice Plants}

According to the method of Zhang et al. (2016), the temperatures of the rice plants were determined from 9: 30 to $10: 30$ during the day and at night (19:30 to 20:30) using an FLIR Therma CAM ${ }^{\mathrm{m}}$ S65 system (FLIR Systems Inc., Portland, OR. USA) with a wide-angle camera lens (18 mm IR-LENS). The camera was set up $1.0 \mathrm{~m}$ away from the rice plants. A black cloth was set up behind the rice plants to minimize interference from other sources when recording the temperature. The data were 
analyzed with Therma CAM Researcher Pro 2.7 software (FLIR Systems).

\section{$\mathrm{H}_{2} \mathrm{O}_{2}$ Measurement}

$\mathrm{H}_{2} \mathrm{O}_{2}$ content was determined according to the method of Brennan and Frenkel (1977) with some modifications. About $0.2 \mathrm{~g}$ of frozen leaves were homogenized in $4 \mathrm{~mL}$ of $10 \mathrm{mmol} \cdot \mathrm{L}^{-1}$ 3-amino-1,2,4-triazole (not cold acetone), and then centrifuged for $25 \mathrm{~min}$ at $6000 \times g$. Thereafter, $1 \mathrm{~mL} 0.1 \%$ titanium tetrachloride dissolved in $20 \%$ $\mathrm{H}_{2} \mathrm{SO}_{4}$ was added to $2 \mathrm{~mL}$ of the supernatant. The reaction solution was further centrifuged to remove undissolved materials, and absorbance was recorded at 410 nm.

\section{Lipid Peroxidation Measurements}

According to the method of Dhindsa et al. (1981), the concentration of thiobarbituric acid reactive substances was determined to estimate MDA content. About $0.2 \mathrm{~g}$ of frozen leaves were homogenized in $2 \mathrm{~mL}$ of $5 \%$ trichloroacetic acid for this process.

\section{Relative Electrical Conductance Measurement}

Relative electrical conductance (REC) was measured by the method of Xiong et al. (2012). About $0.5 \mathrm{~g}$ fresh rice leaves were collected quickly at the end of the heat stress, cut into $25-\mathrm{mm}^{2}$ pieces, and added to a test tube with $12 \mathrm{~mL}$ deionized water for $2 \mathrm{~h}$ at $25^{\circ} \mathrm{C}$. The electrical conductivity of the solution (EC1) was determined with a conductivity meter (DDA-11A; Shanghai Hongyi Instrument Co., Ltd., Shanghai, China) after the incubation. The samples were heated at $80^{\circ} \mathrm{C}$ for $2 \mathrm{~h}$ in their effusates and cooled to $25^{\circ} \mathrm{C}$, and electrical conductivity (EC2) was measured again in the bathing solution. Ion leakage was calculated as the ratio between EC1 and EC2.

\section{Abscisic Acid Measurements}

About $0.2 \mathrm{~g}$ of frozen leaves were weighed and an enzyme-linked immunosorbent assay was used to determine endogenous ABA content according to the method of Yang et al. (2001). All procedures were conducted in accordance with the manufacturer's instructions (China Agricultural University, Beijing, China).

\section{Measurement of ATP and NAD (H) Contents}

Frozen leaves $(0.1 \mathrm{~g})$ were homogenized with $2 \mathrm{~mL}$ of perchloric acid in an ice bath and centrifuged for $10 \mathrm{~min}$ at $8000 \times g$. Then, $2 \mathrm{~mL}$ of $\mathrm{NaOH}$ was added to the supernatant and centrifuged for $10 \mathrm{~min}$ at $8000 \times g$. The supernatant was collected and placed in an ice bath for analysis. An ATP assay kit was used to determine ATP content according to the manufacturer's instructions (Comin Biotechnology Co., Ltd., Suzhou, China).
According to the method of Matsumura and Miyachi (1983), NAD ${ }^{+}$and NADH were extracted with $1 \mathrm{~mL} 0.1$ $\mathrm{mol} \cdot \mathrm{L}^{-1} \mathrm{HCl}$ and $0.1 \mathrm{~mol} \cdot \mathrm{L}^{-1} \mathrm{NaOH}$, respectively. An assay kit was used to determine the $\mathrm{NAD}^{+}$and $\mathrm{NADH}$ contents, according to the manufacturer's instructions (Comin Biotechnology Co., Ltd.).

\section{Leaf Water Potential Measurements}

Leaf water potential was determined according to the method of Chen et al. (2018). The youngest fully expanded leaves were collected $34 \mathrm{~h}$ after heat stress to determine the water potential using a PSYPRO Dew Point Microvoltmeter equipped with a leaf sample chamber (Model C-52, Wescor Co., Logan, UT, USA). Discs of leaves were obtained with a piercer, and placed inside the measurement chamber. The data were recorded after 30-min equilibrium of the microenvironment in the measurement chamber.

\section{Morphology of Bulliform Cells and Leaf Stomata}

The leaf samples used for observing the morphology of bulliform cell were collected from the youngest fully expanded leaves under control conditions. The sections were prepared with a freezing microtome, and then the tissue slices of the bulliform cells were photographed with a fluorescence microscope (DM4000; Leica, Jena, Germany). The area of the bulliform cells was measured using Image J software (National Institutes of Health, Bethesda, MD, USA) by selecting the calculation tool for irregular delineation.

The number of stomata, their opening rate, and their aperture were determined according to the method of Feng et al. (2018), that the youngest fully expanded leaves of the rice plants were detached and immediately immersed in $3.5 \%$ glutaraldehyde in phosphate buffer $(0.1 \mathrm{M}, \mathrm{pH}=7.0)$ at $4{ }^{\circ} \mathrm{C}$. These samples were dehydrated in a Hitachi Model HCP-2 critical point dryer, coated with gold-palladium in the Hitachi Model E-1010 ion sputter for 4-5 min, and observed with a Hitachi Model SU-8010 scanning electron microscope.

\section{Quantitative Real-Time Polymerase Chain Reaction (PCR) Analysis}

Total RNA was extracted from $100 \mathrm{mg}$ of leaves using the TRIpure reagent (Aidlab Biotechnologies, Beijing, China). RNA was converted to first-strand cDNA using the ReverTra Ace qPCR RT Master Mix (TOYOBO, Shanghai, China). The resulting cDNA was used as the template for quantitative PCR amplification in a Thermal Cycler Dice Real Time System II (TaKaRa Biotechnology, Dalian, China) using SYBR Green I (TOYOBO) as the fluorescent reporter. The primers were designed using PRIMER5 software (Rozen and Skaletsky 2000). The primers for the genes examined are listed in 
Supplementary Table 1. The PCR and detection were executed as described previously (Feng et al. 2013). The $2^{-\Delta \Delta C T}$ method was used to analyze the relative transcript levels, and the experiments were conducted in triplicate.

\section{Statistical Analysis}

Data were processed with SPSS software 11.5 (IBM Corp., Armonk, NY, USA) to detect differences. The mean values and standard errors in the figures represent data from three experimental replicates. The $t$-test was conducted for normally distributed data. Two-way analysis of variance with two factors (temperature and treatment) was conducted to compare the differences with a LSD test at $P<0.05$.

\section{Results}

Response of the Rice Plants to Different Temperatures

To investigate the response of rice plants to different temperature stresses, the WT and hts plants were subjected to temperatures of $30^{\circ} \mathrm{C}, 35^{\circ} \mathrm{C}$, and $40^{\circ} \mathrm{C}$ for 72 $\mathrm{h}$, and the plants were subjected to $45^{\circ} \mathrm{C}$ heat stress for $24 \mathrm{~h}$ (Fig. 1a). Temperatures of $30^{\circ} \mathrm{C}$ and $35^{\circ} \mathrm{C}$ caused little injury to either plant, but obvious damage was observed in the $40{ }^{\circ} \mathrm{C}$ and $45^{\circ} \mathrm{C}$ treatments, particularly in the hts plants. Accordingly, no obvious difference in $\mathrm{Fv} /$ Fm was detected between the WT and hts plants under the $30^{\circ} \mathrm{C}$ and $35^{\circ} \mathrm{C}$ conditions (Fig. $1 \mathrm{~b}$ ). However, the $\mathrm{Fv} / \mathrm{Fm}$ values of the hts plants were significantly lower than those of WT plants under temperatures of $40{ }^{\circ} \mathrm{C}$ and $45^{\circ} \mathrm{C}$. In contrast, the MDA content in the leaves of hts plants was higher than that of WT plants under the $40{ }^{\circ} \mathrm{C}$ and $45^{\circ} \mathrm{C}$ treatments (Fig. 1c). No marked differences were detected in REC or chlorophyll content between the control and the $40{ }^{\circ} \mathrm{C}$ heat stressed WT plants, while a remarkable increase was found in hts plants under heat stress compared with the control (Fig. $1 \mathrm{~d}$ and e).

The leaves in both rice genotypes appeared to be flat under the control condition of $30^{\circ} \mathrm{C}$ (Fig. 1f). Semirolled leaves were present on hts plants under heat stress of $40^{\circ} \mathrm{C}$, while the leaves of WT plants remained flat. Interestingly, the area of bulliform cells in WT plants was significantly larger than that of $h t s$ plants under natural conditions (Fig. $1 \mathrm{~g}$ and h). However, the leaf water potential was higher in WT than that in hts plants, particularly under heat stress (Fig. 1i). Aquaporins can maintain water balance in plants under abiotic conditions, and the PIP2 gene has been reported to function in this process (Kaldenhoff et al. 2008; Israel et al. 2019; Zhang et al. 2019). Similarly, a greater increase in expression levels of PIP2 were found in WT than that in $h t s$ plants under heat stress compared with their respective controls (Fig. 1j).
Effect of Heat Stress on Dry Matter Weight Accumulation, Carbohydrate Content, and Metabolism of Rice Plants Sugar allocation and metabolism are important for growth and development of rice plants regardless of the conditions, but they are always disturbed by heat stress (Chen et al. 2019; Islam et al. 2019). Thus, we determined the dry matter weight, carbohydrate content, and genes associated with sucrose transport and metabolism to investigate the changes in sugar transportation and metabolism between WT and hts plants in response to heat stress (Fig. 2). No difference was detected in dry matter weight of the whole plant between the control and heat stressed groups of WT plants (Fig. 2a). However, a notable reduction was found in hts plants under heat stress compared with the control. Similarly, no significant difference in leaf dry matter weight was observed between the control and heat stressed WT plants, while a remarkable decrease was shown in hts plants. However, these results were not found in sheath-stem, where no obvious difference was detected between the control and heat stressed groups in either genotype.

Carbohydrate contents, including non-structural carbohydrates (NSC), starch, soluble sugar, sucrose, glucose, and fructose clearly increased in WT plants under heat stress, compared with their respective controls, whereas such an effect was not observed in hts plants (Fig. 2b). No differences in contents of NSC, starch, sucrose or fructose were detected between the control and heat stress in hts plants. Additionally, soluble sugar and glucose contents decreased significantly in response to heat stress when compared with the control.

The SUT4, SUS2, INV1, and CIN1 genes are responsible for sucrose transport and metabolism. As shown in Fig. 2c, the expression levels of SUT4, SUS2, INV1, and CIN1 increased obviously in WT plants under heat stress compared with the control, while no differences were observed in hts plants except for INVI, which decreased in response to heat stress.

\section{Effect of Heat Stress on Leaf Tissue Temperatures in Rice Plants}

The degree of damage is always associated with leaf tissue temperature in rice plants under heat stress ( $\mathrm{Fu}$ et al. 2016; Wu et al. 2019). Higher tissue temperature not only directly damages rice plants but also consumes more carbohydrates through respiration, which results in energy deficits and heat damage (Baena-González and Sheen 2008; Islam et al. 2018). As shown in Fig. 3, the leaf temperatures of WT plants were lower during the day time than leaves in $h t s$ plants, and the differences were about $1.5{ }^{\circ} \mathrm{C}$ and $2.5^{\circ} \mathrm{C}$ under the control and heat stress conditions, respectively (Fig. 3a and b). No difference in leaf temperature was detected at night between the WT and hts plants under the control condition (Fig. 3c). However, 

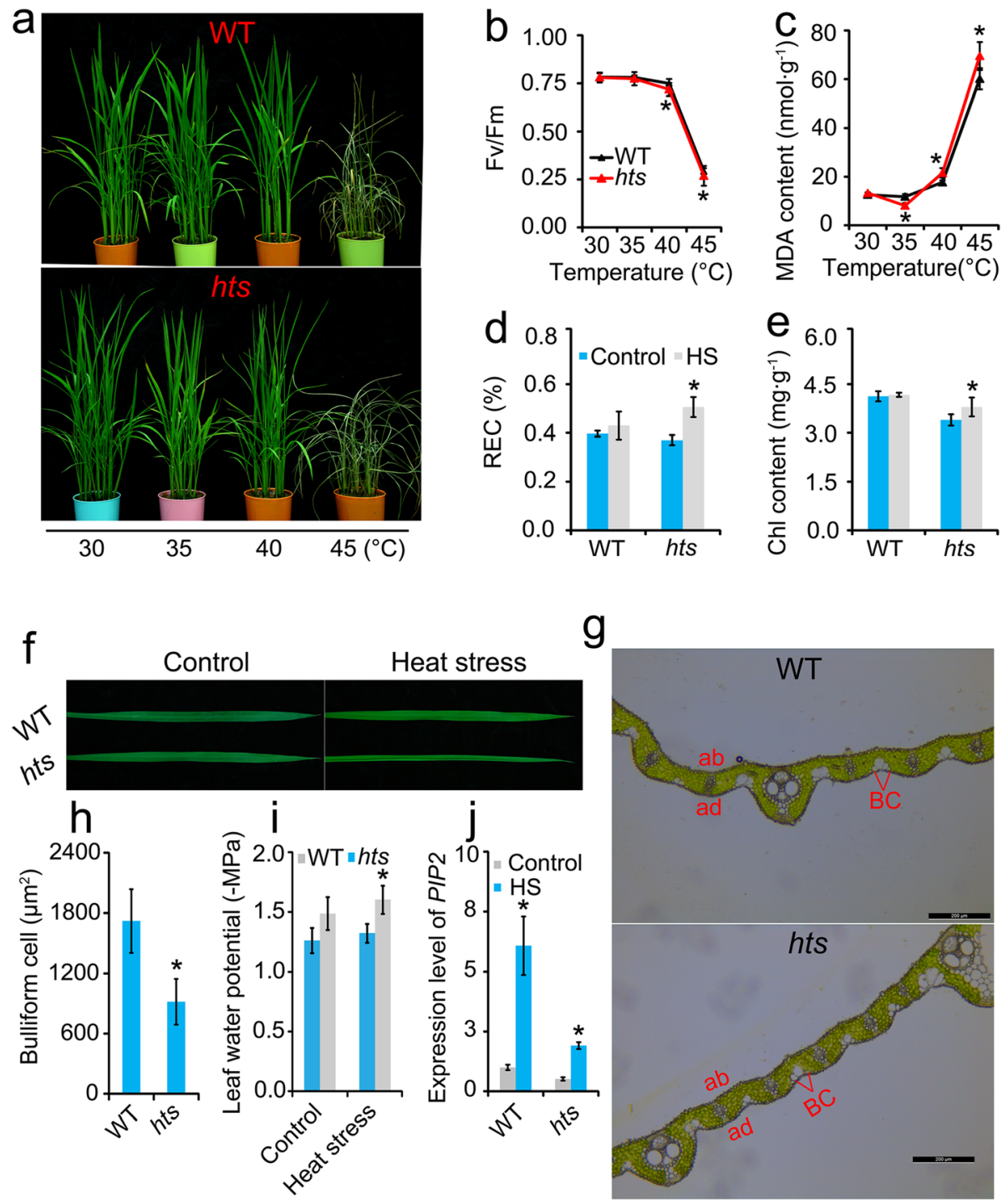

Fig. 1 Responses of rice plants to different temperatures under heat stress conditions. a Photographs of WT and hts plants under different temperature conditions; $\mathbf{b} \mathrm{Fv} / \mathrm{Fm} ; \mathbf{c}$, MDA; d, Relative ion leakage; $\mathbf{e}$, Chlorophyll content. $\mathbf{f}$, Photographs of leaf morphology under control and heat stress conditions; $\mathbf{g}$. Photographs of bullioform cell in leaf of WT and hts plants under control condition. 'ad' stands for adaxial and 'ab' for abaxial, 'BC' for bulliform cells; h, Mean value of area of bulliform cell; i, Relative leaf water potential; j, Expression levels of PIP2. Vertical bars denote standard deviations $(n=3)$. A t-test was conducted to compare the difference between control and heat stress within a cultivar on the same day. ${ }^{*}$ denotes $P<0.05$

the leaf temperature in WT plants was lower by $0.5^{\circ} \mathrm{C}$ than that of hts plants under heat stress.

As the main factors contributing to leaf temperature, stomatal conductance and transpiration rates were determined during the day. Stomatal conductance of leaves in WT plants was significantly higher than that of hts plants (Fig. 3d). No obvious difference was detected in the transpiration rate between the two plants under control conditions, whereas the difference was significant under the heat stressed condition (Fig. 3e). No difference in respiration was detected between WT and hts plants under the control condition, but the respiration rate of $h t s$ plant leaves was significantly higher than that of WT plant leaves under the heat stressed condition (Fig. 3f).

The stomata numbers, stomatal opening rate, and aperture of the leaves were also determined under heat stress during the day (Fig. 3g). Based on the photographs, we found higher numbers of stomata in hts than WT plants (Fig. 3h). In contrast, the stomatal opening rate and stomatal aperture in WT plants were obviously higher than those of hts plants, particularly under heat stress (Fig. 3i and j). 


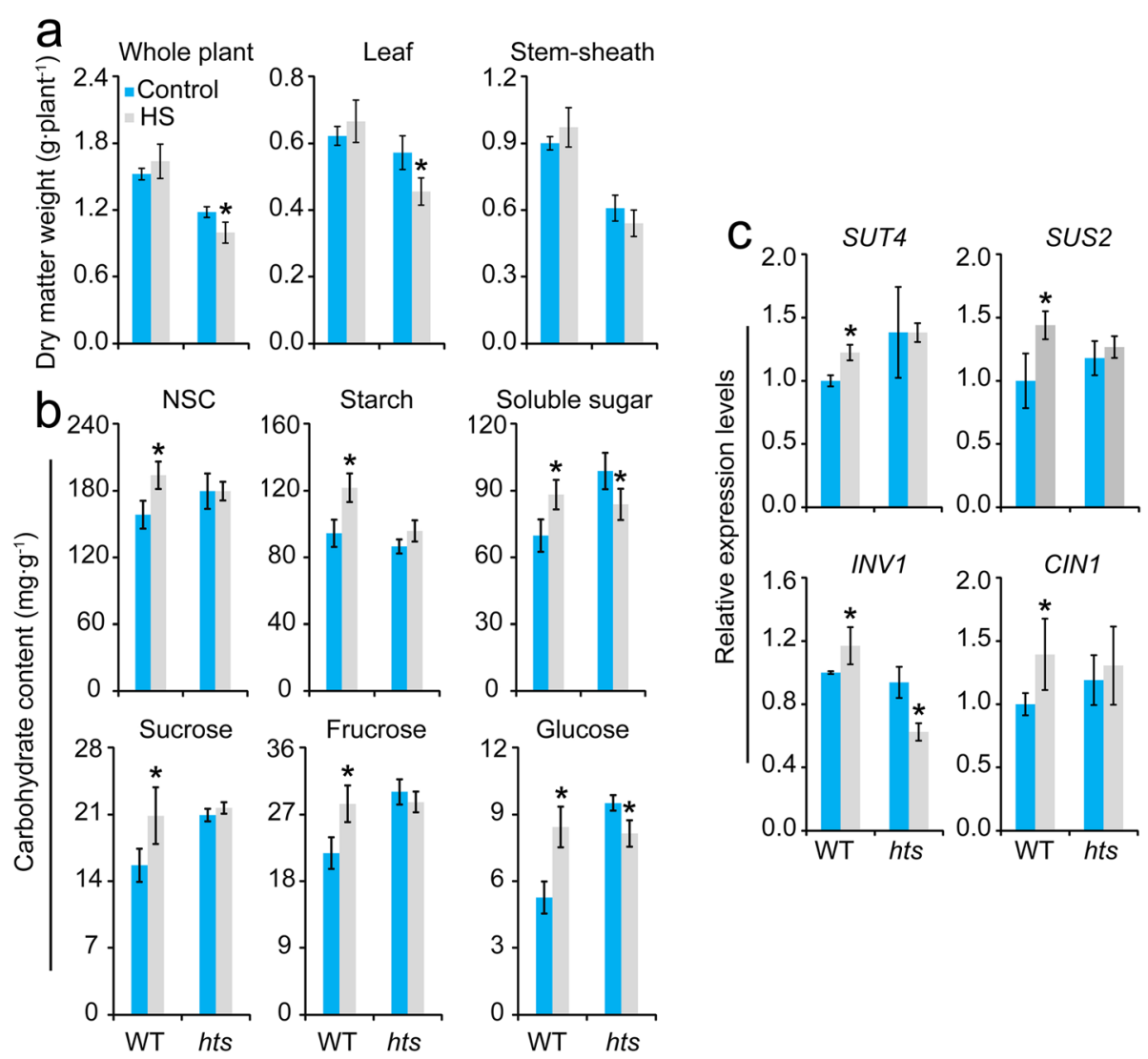

Fig. 2 Effect of heat stress on assimilate accumulation and distribution in rice plants under heat stress. $\mathbf{a}$, Dry matter weight; $\mathbf{b}$, Carbohydrate; $\mathbf{c}$, Expression levels of SUT4, SUS2, CIN1, and INV1. Vertical bars denote standard deviations $(n=3)$. A $t$-test was conducted to compare the difference between the control and heat stressed groups within a cultivar on the same day. ${ }^{*}$ denotes $P<0.05$

Effect of Heat Stress on $\mathrm{ABA}, \mathrm{H}_{2} \mathrm{O}_{2}$, and Heat Shock Proteins of Leaves in Rice Plants

ABA and $\mathrm{H}_{2} \mathrm{O}_{2}$ not only play critical roles in stomatal aperture and transpiration capacity of leaves (Feng et al. 2020; Islam et al. 2018), but also induce the accumulation of HSPs ( $\mathrm{Li}$ et al. 2014). ABA and $\mathrm{H}_{2} \mathrm{O}_{2}$ contents as well as the expression levels of the HSP71.1 and HSP24.1 genes were determined to reveal the relationship among $\mathrm{ABA}, \mathrm{H}_{2} \mathrm{O}_{2}$, and $\mathrm{HSPs}$ in these two rice plants under heat stress. Similar changes in $\mathrm{ABA}$ and $\mathrm{H}_{2} \mathrm{O}_{2}$ were detected in the two plants, in which higher $\mathrm{ABA}$ and $\mathrm{H}_{2} \mathrm{O}_{2}$ contents were found in hts plants than in WT plants regardless of the conditions (Fig. 4a and b). Additionally, greater increases in $\mathrm{ABA}$ and $\mathrm{H}_{2} \mathrm{O}_{2}$ contents were found in hts plants than WT plants under heat stress compared with their respective controls, particularly $34-72 \mathrm{~h}$ after the heat stress. Notably, a greater increase in HSP71.1 and HSP24.1 expression levels was detected in WT than hts plants under heat stress, particularly $48-72 \mathrm{~h}$ after the heat stress (Fig. 4c and d).

\section{Effect of Heat Stress on Energy Homeostasis of Leaves in Rice Plants}

HSPs provide protection against heat stress in plants, but their accumulation is a high cost energy process (Grenert et al. 1997). ATP and NAD (H) contents as well as the expression levels of PARP genes were determined to investigate the effect of heat stress on energy production and consumption in plants (Fig. 5). ATP content decreased markedly in response to heat stress compared with the control in both genotypes, where a greater decrease was found in hts than WT plants during the entire stress period (Fig. 5a). In contrast, a sharp increase in NAD $(\mathrm{H})$ content of leaves was observed in both rice plants under heat stress, and a greater increase was found in WT than hts plants, particularly $72 \mathrm{~h}$ after heat stress (Fig. 5b). PARP is related to energy consumption in plants under abiotic stress (Tiwari et al. 2002; De Block et al. 2011), and no significant differences were observed in PARP1 or PARP2 expression between the control and heat-stressed groups of WT plants, while greater increases were detected in hts plants under heat stress (Fig. 5c and d). 


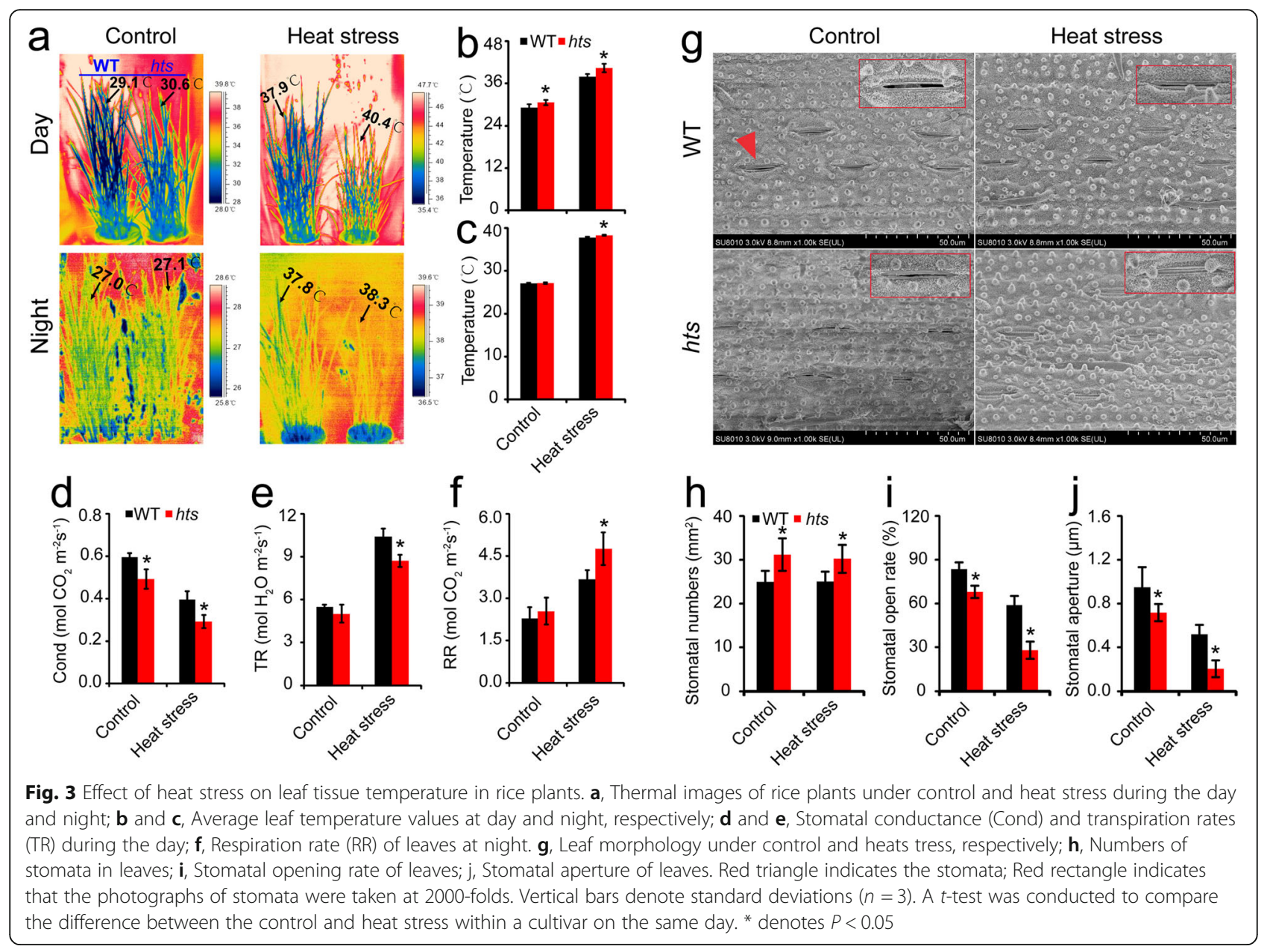

\section{The Function of ABA in Heat Tolerance of $h$ ts Plants under Heat Stress}

According to the above results, ABA could negatively regulate heat acclimation in hts plants with rolled leaves (Fig. 5e). A higher leaf temperature was always observed in hts plants with semi-rolled leaves under the heat stressed condition, which was mainly due to their lower heat dissipation ability and enhanced ABA content in leaves, which, in turn, increased leaf temperature by inducing stomatal closure to reduce the transpiration rate. Higher respiration rates of leaves caused by higher tissue temperatures consume more carbohydrates, resulting in an energy deficit under heat stress, which could impair the ability of the plants to overcome peak stress. Therefore, we hypothesized ABA adversely affected heat acclimation of rice plants with semi-rolled leaves to heat stress.

\section{Effect of ABA on Tissue Temperature of Rice Plant Leaves under Heat Stress}

Different $\mathrm{ABA}$ concentrations were sprayed onto rice plants to reveal the role of $\mathrm{ABA}$ in heat tolerance between
WT and $h t s$ plants under heat stress. Leaf temperatures increased as the ABA concentration was increased in both rice plants regardless of the conditions (Fig. $6 a$ and b). Under heat stress, the leaf temperatures of WT plants increased by $0.1^{\circ} \mathrm{C}, 0.5^{\circ} \mathrm{C}$, and $1.5^{\circ} \mathrm{C}$ in the $1 \mu \mathrm{mol} \cdot \mathrm{L}^{-1}$, $10 \mu \mathrm{mol} \cdot \mathrm{L}^{-1}$, and $100 \mu \mathrm{mol} \cdot \mathrm{L}^{-1} \mathrm{ABA}$ treatments, respectively compared with that of the $0 \mu \mathrm{mol} \cdot \mathrm{L}^{-1} \mathrm{ABA}$ treatment, while those of $h t s$ plants were $0.5^{\circ} \mathrm{C}, 0.7^{\circ} \mathrm{C}$, and $1.8^{\circ} \mathrm{C}$, respectively (Fig. 6c). At night, the leaf temperatures in WT plants sprayed with $0 \mu \mathrm{mol} \cdot \mathrm{L}^{-1}, 1 \mu \mathrm{mol} \cdot \mathrm{L}^{-1}$, $10 \mu \mathrm{mol} \cdot \mathrm{L}^{-1}$, and $100 \mu \mathrm{mol} \cdot \mathrm{L}^{-1} \mathrm{ABA}$ were about $36.7^{\circ} \mathrm{C}$, $37.2^{\circ} \mathrm{C}, 37.4{ }^{\circ} \mathrm{C}$, and $37.6^{\circ} \mathrm{C}$ under heat stress, respectively, while in hts plants the temperatures were $37.6^{\circ} \mathrm{C}, 37.7^{\circ} \mathrm{C}$, $37.9^{\circ} \mathrm{C}$, and $38.2^{\circ} \mathrm{C}$ (Fig. $6 \mathrm{~d}$ ). Stomatal conductance and transpiration rates decreased significantly in response to ABA in both genotypes, particularly in plants treated with $100 \mu \mathrm{mol} \cdot \mathrm{L}^{-1}$ ABA (Fig. 6e and f).

Effect of $A B A$ on $\mathrm{Fv} / \mathrm{Fm}$, Sugar Transport, and Metabolism of Rice Plant Leaves under Heat Stress

The Fv/Fm is reported to be susceptible to heat stress and is commonly used to evaluate heat tolerance in 

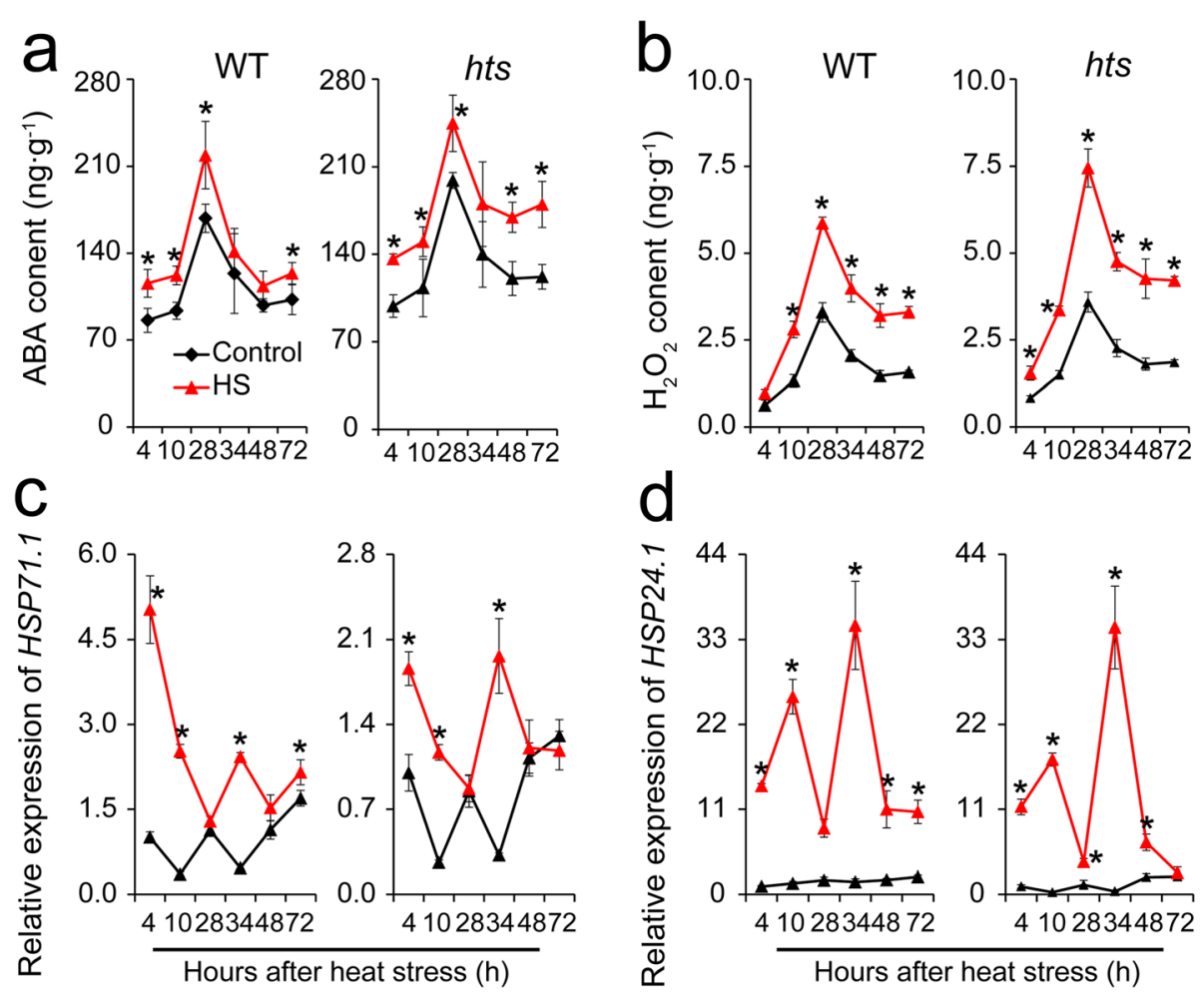

Fig. 4 Changes in of $A B A, H_{2} \mathrm{O}_{2}$, and heat shock proteins in leaves of rice plants under heat stress. a, ABA content; $\mathbf{b}, \mathrm{H}_{2} \mathrm{O}_{2}$ content; $\mathbf{c}$, Relative expression level of HSP71.1; d, Relative expression level of HSP24.1. Vertical bars denote standard deviations $(n=3)$. A $t$-test was conducted to compare the differences between control and heat stress within a cultivar on the same day. ${ }^{*}$ denotes $P<0.05$

plants (Poudyal et al. 2019). As shown in Fig. 7a, the Fv/ Fm value decreased significantly in response to heat stress. Notably, the decrease in Fv/Fm by heat stress was reversed by $\mathrm{ABA}$ in WT plants. In contrast, the $\mathrm{Fv} / \mathrm{Fm}$ values in $h$ ts plants decreased as the ABA concentration was increased under heat stress, particularly the $10 \mu \mathrm{mol} \cdot \mathrm{L}^{-1}$ and $100 \mu \mathrm{mol} \cdot \mathrm{L}^{-1} \mathrm{ABA}$ treatments.

The contents of NSC, starch, and soluble sugar in the leaves of WT plants decreased with the increase in ABA concentration under control conditions (Fig. $7 \mathrm{~b}, \mathrm{c}$ and $\mathrm{d}$ ). In contrast, there was almost no difference in contents of NSC, starch, or soluble sugar among these treatments of hts plants under the control conditions. Interestingly, in WT plants, the contents of NSC, starch, and soluble sugar increased as the ABA concentrations was increased under heat stress, while they decreased in hts plants, except for soluble sugar. The expression levels of genes related the sucrose transport and metabolism, such as SUT4, SUS2, INV1, and CIN1 increased in response to ABA except for CIN1 in WT plants under the control conditions (Fig. 7e-h). Interestingly, these genes in WT plants were induced by heat stress or ABA, while they decreased significantly in hts plants in response to ABA compared with their respective controls.
Effect of ABA on Energy Production and Consumption of Leaves in Rice Plants under Heat Stress

Regardless of the conditions, ATP content increased with increased ABA concentration (Fig. 8a). Interestingly, ATP content in WT plants increased significantly in response to heat stress, whereas no difference was detected between the control and heat stress in hts plants except for the $100 \mu \mathrm{mol} \cdot \mathrm{L}^{-1} \mathrm{ABA}$ treatment. No significant differences in NAD $(\mathrm{H})$ were detected among the ABA treatments under the control condition except for the $100 \mu \mathrm{mol} \cdot \mathrm{L}^{-1} \mathrm{ABA}$ treatment in WT plants, which was significantly higher than that of the $0 \mu \mathrm{mol} \cdot \mathrm{L}^{-1} \mathrm{ABA}$ treatment (Fig. 8b). A sharp increase in NAD $(\mathrm{H})$ content was detected in WT plants under heat stress, especially the $10 \mu \mathrm{mol} \cdot \mathrm{L}^{-1} \mathrm{ABA}$ treatment, while NAD (H) content decreased in hts plants as ABA concentration was increased. The PARP genes were activated by heat stress in both genotypes, but different responses to ABA were found between the WT and hts plants (Fig. 8c and d). Compared with their respective controls, the lower increase in the expression levels of PARP1 and PARP2 were detected in WT plants than hts plants under heat stress, particularly in the $100 \mu \mathrm{mol} \cdot \mathrm{L}^{-1} \mathrm{ABA}$ treatment. 

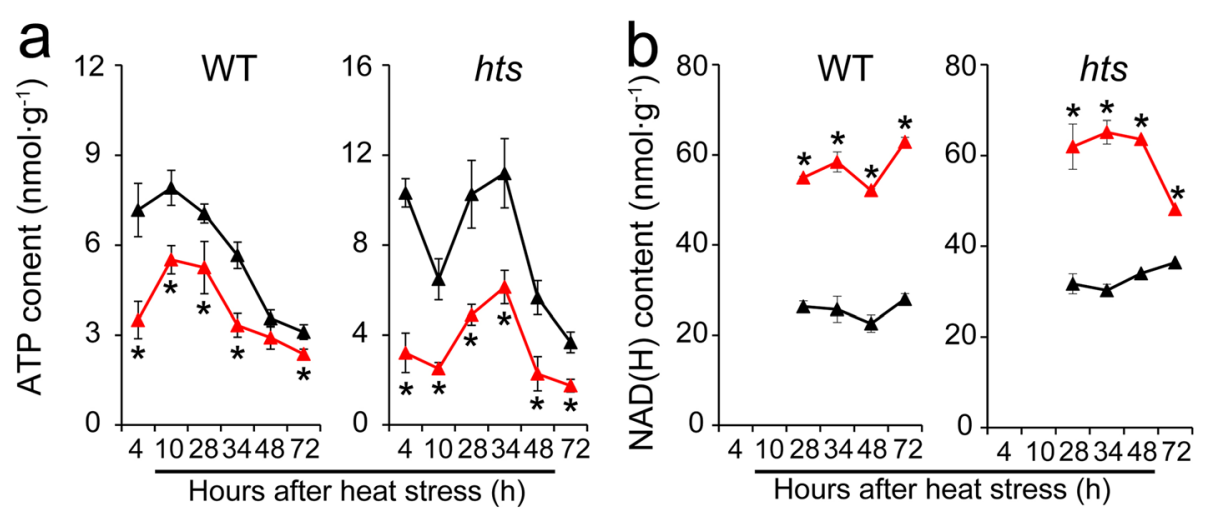

C

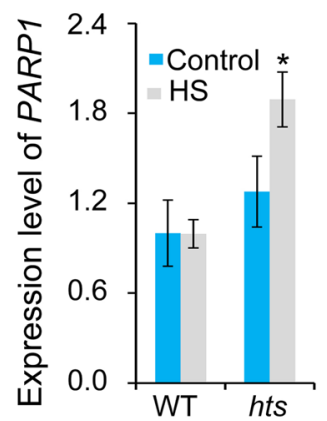

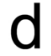

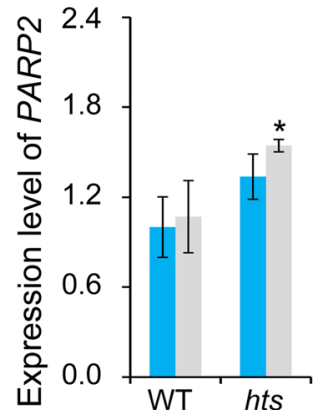

e

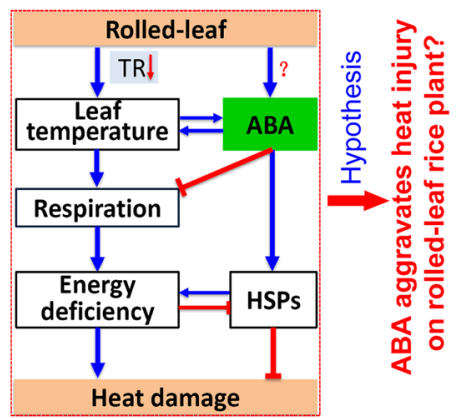

Fig. 5 Effect of heat stress on energy homeostasis in leaves of rice plants. a, ATP content; $\mathbf{b}$, NAD (H) content; $\mathbf{c}$, Relative expression level of PARP1; d, Relative expression level of PARP2; $\mathbf{e}$, The possible function of ABA in rice plants with semi-rolled leaves under heat stress. Significantly higher tissue temperatures occurred in the rolled leaf rice plants (hts) under heat stress, which was mainly ascribed to lower heat dissipation ability. At the same time, ABA content increased in the rolled leaf plants, which, in turn, increased leaf temperature by reducing the stomatal conductance and transpiration rates. Such an effect could increase the respiration rate of leaves. Therefore, more carbohydrates were consumed, resulting in an energy deficit under heat stress, which caused damage to the rice plants with rolled leaves. Therefore, we inferred that higher ABA content accelerated heat injury in rice plants with rolled leaves. Vertical bars denote standard deviations $(n=3)$. A $t$-test was conducted to compare the difference between the control and heat stressed groups within a cultivar on the same day. ${ }^{*}$ denotes $P<0.05$

\section{Effect of ABA on the Relative Expression Levels of HSP Genes in Leaves under Heat Stress}

Under the control condition, the expression levels of HSP71.1 and HSP24.1 increased as ABA concentration was increased, while no difference was detected among the ABA treatments except for HSP71.1 in hts plants (Fig. 8e and f). The expression levels of HSP71.1 and HSP24.1 in WT plants increased significantly under heat stress in response to ABA. Similarly, heat stress induced expression of HSP71.1 and HSP24.1 in hts plants, whereas the increases in expression levels decreased as ABA concentration was increased under heat stress. Additionally, a greater increase in HSP71.1 and HSP24.1 expression levels were found in WT than hts plants under heat stress compared with their respective controls, particularly the $100 \mu \mathrm{mol} \cdot \mathrm{L}^{-1} \mathrm{ABA}$ treatment.

\section{Discussion}

\section{Contribution of the Semi-Rolling Trait Leaf to Heat Resistance in Rice Plants}

The present results indicate that more damage was caused by heat stress in hts plants with semi-rolled leaves than in WT plants at $40^{\circ} \mathrm{C}$ or $45^{\circ} \mathrm{C}$ (Fig. 1), which was consistent with our previous results (Zhang et al. 2018). The semi-rolled trait leaf may have contributed to lower heat tolerance in hts plants (Fig. 1a and b). This finding was inconsistent with previous results that the rolled leaf trait confers resistance to plants against drought and heat stress by reducing transpiration and water loss from plants to improve water use efficiency (O'Toole and Cruz 1980; Sarieva et al. 2010; Buitrago et al. 2016; Zhang et al. 2018; Cal et al. 2019). However, this function of rolled leaves enhances leaf temperatures, resulting in more damage to the rice plants under a heat stress condition (Fig. 3). Heat stress causes more damage to spikelets than leaves of rice plants mainly because of the higher tissue temperatures in spikelets than leaves (Zhang et al. 2016).

Indeed, the rolled leaf trait in hts plants was only found under the heat stress condition (Fig. 1f). According to the present results (Fig. 1 and Fig. S1), bulliform cells might not be involved in the process of leaf rolling in hts plants under heat stress (Li et al. 2010). Notably, 

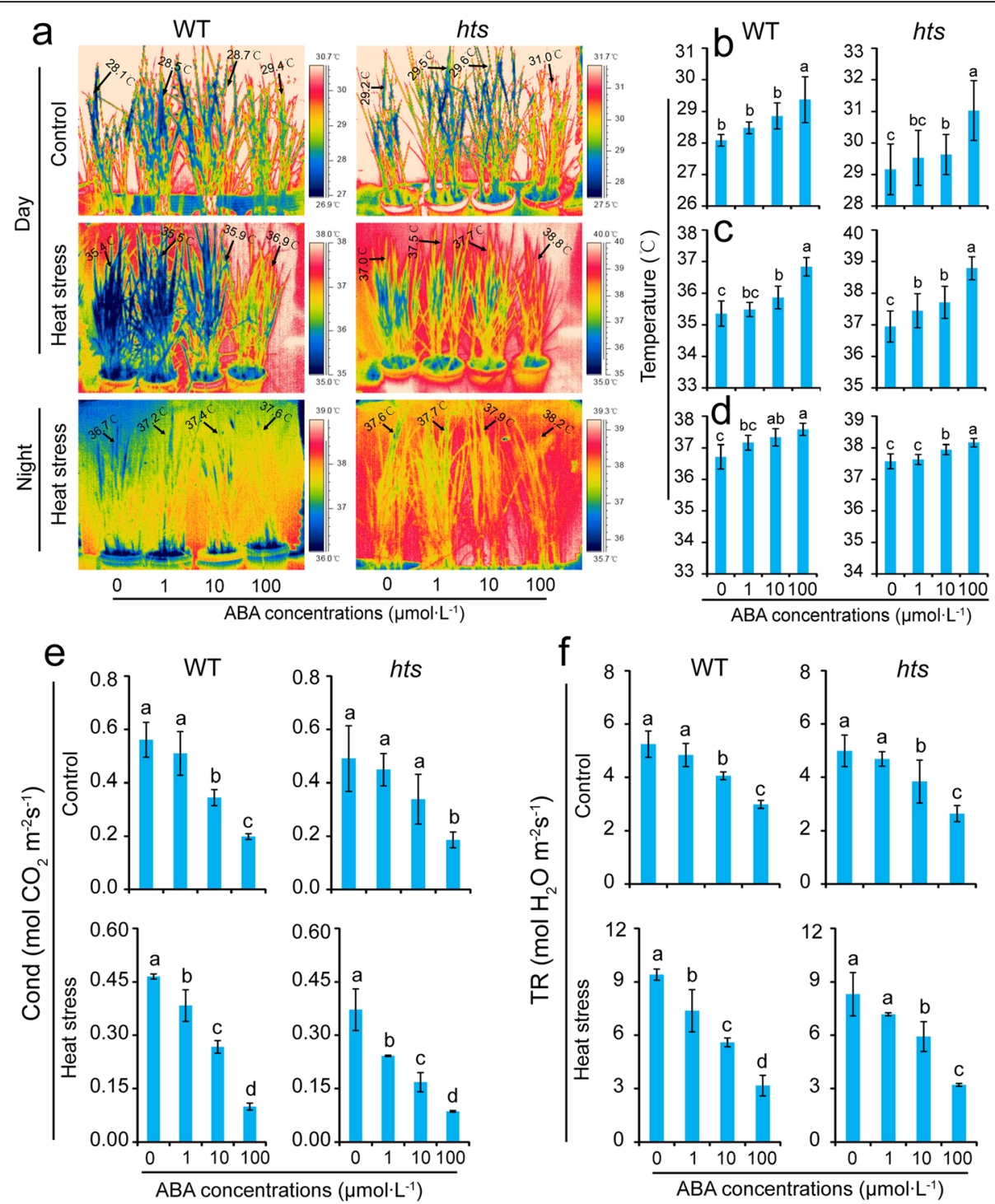

Fig. 6 Changes in tissue temperatures, stomatal conductance, and transpiration rates of rice plant leaves caused by ABA under heat stress. a, Thermal images of rice plants under the control and heat stress treatments during the day and night; $\mathbf{b}$, Average leaf tissue temperature values at day under control conditions; $\mathbf{c}$, Average leaf tissue temperature values at day under heat stress; $\mathbf{d}$, Average leaf tissue temperature values at night under heat stress; e, Stomatal conductance (Cond); $\mathbf{f}$, Transpiration rate (TR). Vertical bars denote standard deviations $(n=10$ or 3$)$. Different letters indicate significant differences among ABA treatments under the control and heat stress conditions within a genotype by two-way analysis of variance for two factors (temperature and treatment) $(P<0.05)$

markedly greater decreases in leaf water potential were found in hts than WT plants under heat stress (Fig. 1i), which could explain the changes in leaf morphology between the two genotypes (Fig. 1a and f). We inferred that aquaporins might play critical roles in this process, as they could maintain water balance in plants under abiotic stress by reducing water loss from leaves and enhancing water uptake at the roots (Moshelion et al. 2015; Maurel et al. 2016; McGaughey et al. 2018; Chen et al. 2018; Franzini et al. 2019; Quiroga et al. 2019). The present results indicate that a significant increase in OsPIP2 expression level was detected in leaves of WT plants than that in hts plants under the heat stress condition (Fig. 1j). This was consistent with the result that aquaporins are induced in strawberry plants to acquire systemic thermotolerance (Christou et al. 2014). However, this gene could be induced by ABA in either plant, regardless of the conditions, while the leaf water potential in both rice plants decreased as ABA concentration was increased (Fig. S5). This finding suggests that OsPIP2 might also be induced in roots to enhance water uptake under heat stress.

Aquaporins may function in heat tolerance of these two plants. However, the data are insufficient to confirm 

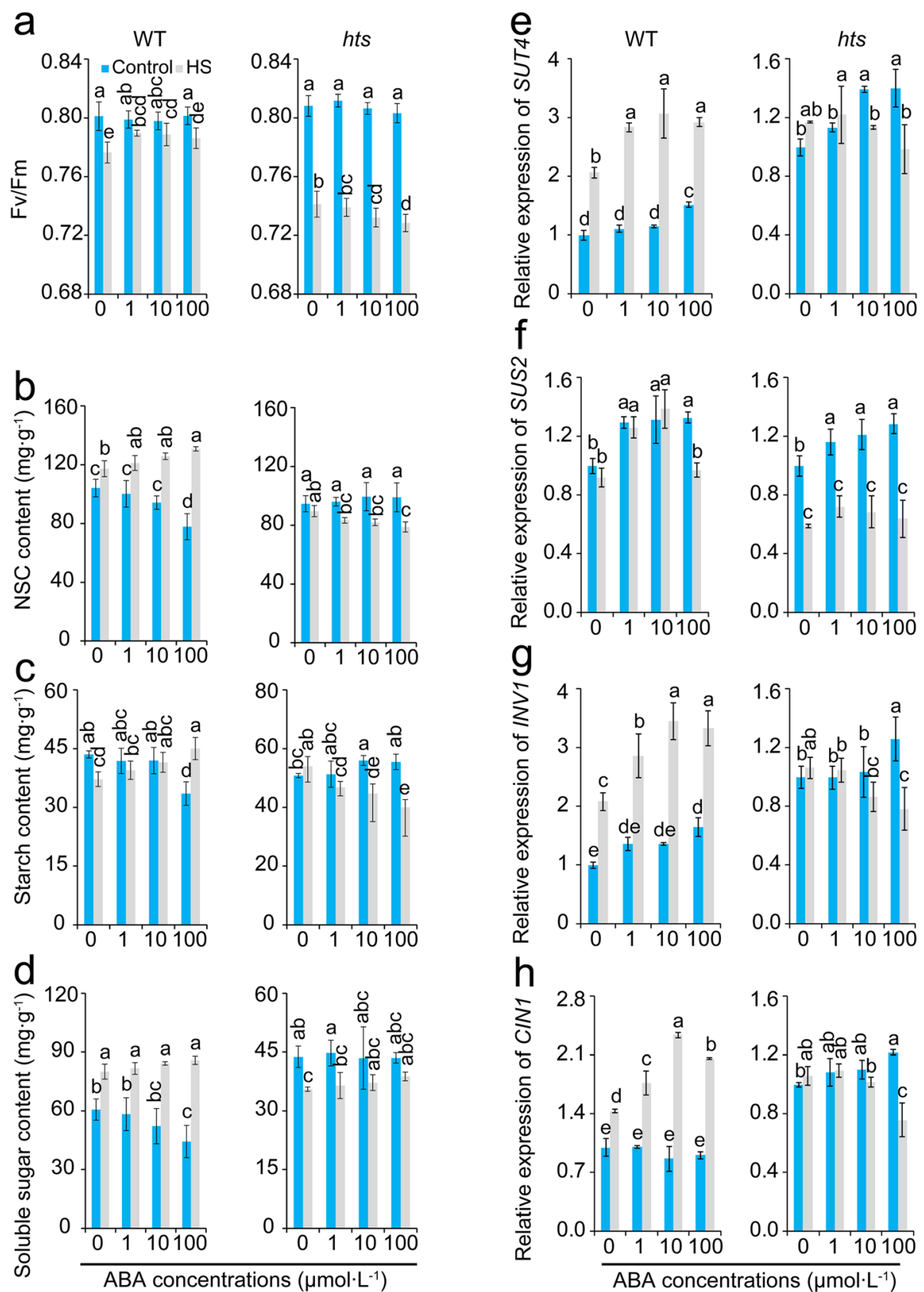

Fig. 7 Effect of ABA on Fv/Fm, carbohydrate content and metabolism of leaves in rice plants under heat stress. $\mathbf{a}$, Fv/Fm; b, NSC content; $\mathbf{c}$, starch content; $\mathbf{d}$, soluble sugar content; $\mathbf{e}$, Relative expression level of SUT4; $\mathbf{f}$, Relative expression level of SUS2; $\mathbf{g}$, Relative expression level of INVI; $\mathbf{h}$, Relative expression level of CIN1. Vertical bars denote standard deviations $(n=3)$. Different letters indicate a significant difference among ABA treatments under the control and heat-stressed conditions within a genotype by two-way analysis of variance for two factors (temperature and treatment) $(P<0.05)$

this hypothesis, and thus the mechanism underlying heat tolerance between these two rice plants remains unclear. Many genes, including TT1 and ERECTA have been identified to confer heat tolerance in rice, Arabidopsis, tomato, and other species ( $\mathrm{Li}$ et al. 2015; Shen et al. 2015; Jacob et al. 2017; Brzezinka et al. 2019; Rytz et al. 2018). These genes provide protection against heat stress in plants or enhance their biomass under high temperature conditions. However, the genes controlling the rolled-leaf of hts plants and heat tolerance in these two rice plant genotypes have been not cloned. Therefore, we are planning to clone the genes through an RFLP map from a DH population. Thereafter, transcriptome, proteome, metabolome, and yeast-two-hybrid 

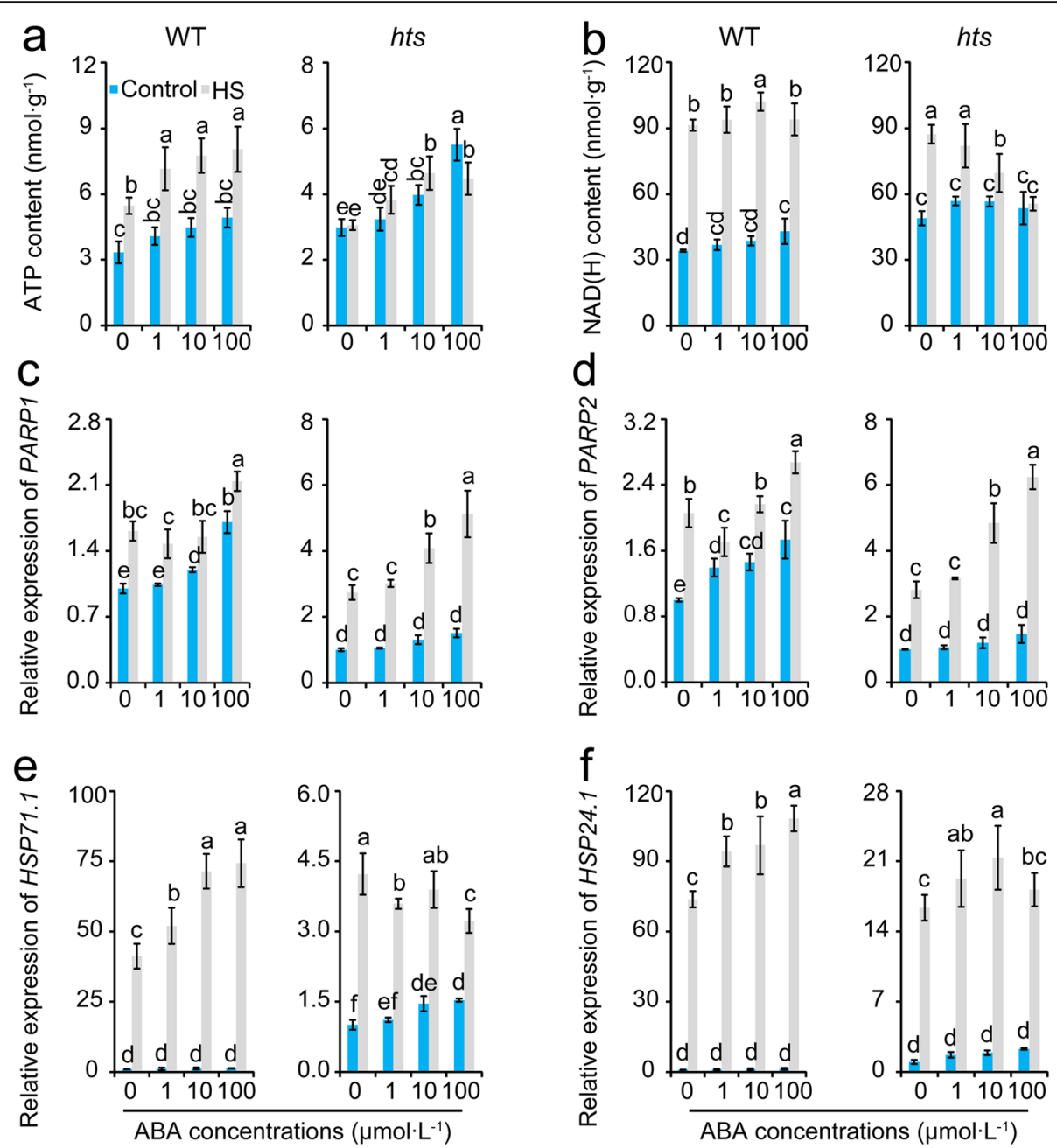

Fig. 8 Changes in ATP and NAD $(H)$ contents as well as the expression levels of HSP genes in leaves of rice plants in response to ABA under heat stress. a, ATP content; b, NAD (H) content; $\mathbf{c}$, Relative expression level of PARP1; $\mathbf{d}$, Relative expression level of PARP2; e, Relative expression level of HSP71.1; $\mathbf{f}$, Relative expression level of HSP24.1. Vertical bars denote standard deviations ( $n=3$ ). Different letters indicate a significant difference among the ABA treatments under the control and heat-stressed conditions within a genotype by two-way analysis of variance for two factors (temperature and treatment) $(P<0.05)$

assays will be used to investigate the functions of the genes in heat tolerance as well as their response to ABA under heat stress.

\section{The Negative Role of ABA in Conferring Heat Tolerance in Rolling Leaf Rice Plants}

In this study, higher $\mathrm{ABA}$ and $\mathrm{H}_{2} \mathrm{O}_{2}$ levels in leaves were shown in hts than in WT plants under heat stress (Fig. $4 \mathrm{a}$ and $\mathrm{b}$ ), suggesting that $\mathrm{ABA}$ was a negative regulator of hts heat tolerance. This hypothesis was confirmed by the present results, that the $\mathrm{Fv} / \mathrm{Fm}$ values of $h$ ts plant leaves decreased as exogenous ABA concentration was increased (Fig. 7a). Clearly, this finding was inconsistent with the result that $\mathrm{ABA}$ confers heat tolerance in plants (Li et al. 2014; Suzuki et al. 2016; Cho et al. 2018; Hu et al. 2018; Islam et al. 2019). These contradictory results depended on the morphology of the leaves under heat stress, as heat tolerance was enhanced in WT plants by exogenous ABA (Fig. 7a). Importantly, similar results were also found in the IR64 (a wild type), rolled leaf mutant RL241, and RL291 plants treated with ABA under heat stress (Figs. S3 and S4). Therefore, the increase in ABA level in hts plants was the result of heat damage, rather than a protective strategy against heat stress.

The negative role of $\mathrm{ABA}$ in the heat response of $h t s$ plants might be related with an energy deficit. It has been well documented that accumulation of HSPs is important to tolerate heat stress (Islam et al. 2019), which can be induced by $\mathrm{ABA}, \mathrm{H}_{2} \mathrm{O}_{2}$, and high temperatures (Li et al. 2014). However, greater increases in the relative expression levels of HSP71.1 and HSP24.1 were found in WT than hts plants under heat stress (Fig. 4c and d), 
which was inconsistent with the previous results ( $\mathrm{Li}$ et al. 2014; Isalm et al. 2019). Indeed, the accumulation of HSPs is a high energy cost process that can be inhibited by the energy deficit caused by heat stress. The greater decreases in dry matter weight, carbohydrates, ATP, and NAD $(\mathrm{H})$ were showed in hts than WT plants under heat stress (Figs. 2, 4 and 5), suggesting higher energy costs were showed in hts plants with semi-rolled leaves under heat stress, which might be mainly due to higher leaf temperatures and respiration (Fig. 3). This hypothesis was confirmed by the present results, that the carbohydrate, ATP, and NAD $(\mathrm{H})$ contents decreased in hts plants as the ABA concentration increased under heat stress (Figs. 7 and 8). Accordingly, the increased expression levels of HSP71.1 and HSP24.1 decreased significantly in hts plants under heat stress as the ABA concentration was increased (Fig. 8e and f). Notably, such effects caused by ABA were not found in WT plants.

Higher energy cost in hts plants under heat stress might be related to PARP. It has been reported that silencing AtPARP1 or AtPARP2 in Arabidopsis enhances plant tolerance to drought, high light, and heat stress (Vanderauwera et al. 2007; Briggs and Bent 2011; Rissel et al. 2017). Plants with reduced PARP activity consume less NAD $(\mathrm{H})$ in stressful environments to improve their energy-use efficiency by reducing over-active mitochondrial respiration and ROS production (Tiwari et al. 2002; De Block et al. 2011). The present results indicate that greater increases in PARP1 and PARP2 expression levels were found in $h t s$ than WT plants under heat stress (Fig. $5 \mathrm{c}$ and $\mathrm{d}$ ). Importantly, the expression levels of the PARP genes increased as ABA concentration was increased in both WT and hts plants (Fig. 8c and d), suggesting that PARP could be activated by ABA. However, this effect depended on the genotype, which might be due to different leaf tissue temperatures caused by heat stress or ABA (Fig. 6a-d).

\section{Conclusion}

Heat stress caused more damage to hts plants with semirolled leaves than WT plants with flat leaves, which was mainly ascribed to higher tissue temperatures and respiration rates as well as lower transpiration and stomatal conductance rates of leaves. Higher increases in levels of ABA and $\mathrm{H}_{2} \mathrm{O}_{2}$ were found in hts than WT plants under heat stress compared with their respective controls. However, greater increase in contents of dry matter weight, carbohydrates, ATP, and NAD $(\mathrm{H})$ as well as expression levels of HSP71.1 and HSP24.1 were observed in WT than hts plants. These results suggest that ABA negatively regulates heat tolerance in hts plants. This hypothesis was confirmed by the further results that the increases in $\mathrm{Fv} / \mathrm{Fm}$, carbohydrates, ATP, and NAD $(\mathrm{H})$ as well as the expression levels of HSP71.1 and HSP24.1 in hts plants increased in response to exogenous $\mathrm{ABA}$ in WT plants, while the increases were reduced in hts plants. Therefore, we infer that ABA negatively modulates semi-rolled leaf rice against heat stress by enhancing leaf temperature and reducing transpiration, resulting in an energy deficiency.

\section{Supplementary information}

Supplementary information accompanies this paper at https://doi.org/10. 1186/s12284-020-00379-3.

\begin{abstract}
Additional file 1: Fig. S1. Effect of heat stress on the expression levels of genes associated with bulliform cells in leaves of rice plants. a, Relative expression level of Tid1; b, Relative expression levels of ACL1. Vertical bars denote standard deviations $(n=3)$. A t-test was conducted to compare the difference between the control and heat stressed groups within a cultivar on the same day. ${ }^{*}$ denotes $P<0.05$.

Additional file 2: Figure S2. Effect of heat stress on the expression levels of genes associated with aquaporins in leaves of rice plants. a, Relative expression level of TIP1; b, Relative expression level of TIP4. Vertical bars denote standard deviations $(n=3)$. A $t$-test was conducted to compare the difference between the control and heat stressed groups within a cultivar on the same day. ${ }^{*}$ denotes $P<0.05$
\end{abstract}

Additional file 3: Figure S3 Leaf mophology of IR64 and its mutant RL241 under control conditions.

Additional file 4: Figure S4. Effect of $A B A$ on tissue temperature and Fv/Fm of leaves in IR64, RL241 and RL291 plants under heat stress. a and $\mathrm{b}$, Thermal images of rice plants under the heat stress and control treatments without ABA treatment, respectively; $c$ and $d$, Thermal images of IR64 and RL241 plants under the control with ABA treatments; e and f, Thermal images of IR64 and RL241 plants under heat stress with ABA treatments; g, Leaf temperature of IR64 and RL241 without ABA treatment; $\mathrm{h}-\mathrm{j}$; Leaf temperature of IR64 and RL241 with ABA treatments; $\mathrm{i}-\mathrm{n}, \mathrm{FV} / \mathrm{Fm}$ of IR64, RL241 and RL291. Vertical bars denote standard deviations (Tissue temperature, $n=10 ; \mathrm{Fv} / \mathrm{Fm}, n=5$ ). Different letters indicate a significant difference among the ABA treatments under the control and heat-stressed conditions within a genotype by two-way analysis of variance for two factors (temperature and treatment) $(P<0.05)$

Additional file 5: Figure S5. Effect of ABA on expression levels of the PIP2 gene and water potential of leaves in rice plants under heat stress. a and $b$, Relative expression of PIP2; $c$ and $d$, Leaf water potential. Vertical bars denote standard deviations ( $P I P 2, n=3$; Leaf water potential, $n=4$ ). Different letters indicate a significant difference among the ABA treatments under the control and heat-stressed conditions within a genotype by two-way analysis of variance for two factors (temperature and treatment) $(P<0.05)$.

Additional file 6: Table S1. Primer sequences used in $\mathrm{QRT}$-PCR.

\section{Abbreviations}

ABA: Abscisic acid; Fv/Fm: Maximum fluorescence quantum efficiency; HS: Heat stress; HSP: Heat shock protein; hts: High temperature susceptible; MDA: Malondialdehyde; NSC: Non-structural carbohydrates; PARP: Poly (ADPRibose) Polymerases; WT: wild type

\section{Acknowledgements}

Not applicable.

\section{Authors' Contributions}

Longxing Tao, Guanfu Fu, Shaobing Peng, and Guangheng Zhang conceived the original research plan and supervised the research work; Guangyan Li, Caixia Zhang, Guanfu Fu, Tingting Chen, Baohua Feng, and Weimeng Fu performed research; Guangyan Li, Caixia Zhang, and Guanfu Fu analyzed the data and wrote the paper. All authors read and approved the final manuscript. 


\section{Funding}

This work was funded by the National Food Science and Technology Project (Grant 2017YFD0300100), National Natural Science Foundation of China (Grant No.31570184, 31671619 and 31561143003), Zhejiang Provincial Natural Science Foundation, China (LQ18C130003; LY19C130006), The Central Public Interest Research Institute Special Fund in China (Grant No. 2017RG004-1), The National Rice Industry Technology System (CARS-1).

\section{Availability of Data and Materials}

The datasets supporting the conclusions of this article are included with in the article (and its additional files).

\section{Ethics Approval and Consent to Participate}

Not applicable.

\section{Consent for Publication}

Not applicable.

\section{Competing Interests}

The authors declare that they have no competing interests.

\begin{abstract}
Author details
${ }^{1}$ National Key Laboratory of Rice Biology, China National Rice Research Institute, Hangzhou 310006, Zhejiang, China. ${ }^{2}$ Crop Production and Physiology Center (CPPC), College of Plant Science and Technology, Huazhong Agricultural University, Wuhan 430070, Hubei, China. ${ }^{3}$ State Key Laboratory of Crop Biology and College of Agronomy, Shandong Agricultural University, Tai'an 271018, Shandong, China.
\end{abstract}

\section{Received: 3 October 2019 Accepted: 28 January 2020}

Published online: 13 March 2020

\section{References}

Albertos P, Wagner K, Poppenberger B (2019) Cold stress signalling in female reproductive tissues. Plant Cell Environ 42(3):846-853

Baena-González E, Sheen J (2008) Convergent energy and stress signaling. Trends Plant Sci 13(9):474-482

Brennan T, Frenkel C (1977) Involvement of hydrogen peroxide in the regulation of senescence in pear. Plant Physiol 59(3):411-416

Briggs AG, Bent AF (2011) Poly (ADP-ribosyl) ation in plants. Trends Plant Sci 16(7):372-380

Brzezinka K, Altmann S, Bäurle I (2019) BRUSHY1/TONSOKU/MGOUN3 is required for heat stress memory. Plant Cell Environ 42:771-781

Buitrago MF, Groen TA, Hecker CA, Skidmore AK (2016) Changes in thermal infrared spectra of plants caused by temperature and water stress. ISPRS J Photogramm 111:22-31

Cal AJ, Sanciangco M, Rebolledo MC, Luquet D, Torres RO, McNally KL, Henry A (2019) Leaf morphology, rather than plant water status, underlies genetic variation of rice leaf rolling under drought. Plant Cell Environ 42:1532-1544

Chen T, Feng B, Fu W, Zhang C, Tao L, Fu G (2018) Nodes protect against drought stress in rice (Oryza sativa) by mediating hydraulic conductance. Environ Exp Bot 155:411-419

Chen T, Li G, Islam MR, Fu W, Feng B, Tao L, Fu G (2019) Abscisic acid synergizes with sucrose to enhance grain yield and quality of rice by improving the source-sink relationship. BMC Plant Biol 19:525

Cho SH, Von Schwartzenberg K, Quatrano R (2018) The role of abscisic acid in stress tolerance. Annu Plant Rev 36:282-297

Christou A, Filippou P, Manganaris GA, Fotopoulos V (2014) Sodium hydrosulfide induces systemic thermotolerance to strawberry plants through transcriptional regulation of heat shock proteins and aquaporin. BMC Plant Biol 14(1):42

De Block M, Van Lijsebettens M (2011) Energy efficiency and energy homeostasis as genetic and epigenetic components of plant performance and crop productivity. Curr Opin Plant Biol 14(3):275-282

Dhindsa RS, Plumb-Dhindsa P, Thorpe TA (1981) Leaf senescence: correlated with increased levels of membrane permeability and lipid peroxidation, and decreased levels of superoxide dismutase and catalase. J Exp Bot 32(1):93101

Ding W, Song L, Wang X, Bi Y (2010) Effect of abscisic acid on heat stress tolerance in the calli from two ecotypes of phragmites communis. Biol Plant 54(4):607-613
Dröge-Laser W, Weiste C (2018) The C/S1 bZIP network: a regulatory hub orchestrating plant energy homeostasis. Trends Plant Sci 23(5):422-433

Dubois M, Gilles K, Hamilton J, Rebers P, Smith F (1956) Colorimetric method for determination of sugars and related substances. Anal Chem 28:350-356

Feng BH, Li GY, Islam M, Fu WM, Zhou YQ, Chen TT, Tao LX, Fu GF (2020) Strengthened antioxidant capacity improves photosynthesis by regulating stomatal aperture and ribulose-1, 5-bisphosphate carboxylase/oxygenase activity. Plant Sci 290:110245

Feng BH, Yang Y, Shi YF, Shen HC, Wang HM, Huang QN, Xu X, Lü XG, Wu JL (2013) Characterization and genetic analysis of a novel rice spotted-leaf mutant HM47 with broad-spectrum resistance to Xanthomonas oryzae pv. Oryzae. J Integr Plant Biol 55(5):473-483

Feng BH, Zhang CX, Chen TT, Zhang XF, Tao LX, Fu GF (2018) Salicylic acid reverses pollen abortion of rice caused by heat stress. BMC Plant Biol 18:245

Flaherty KM, DeLuca-Flaherty C, McKay DB (1990) Three-dimensional structure of the ATPase fragment of a 70K heat-shock cognate protein. Nature 346(6285): 623-628

Franzini Vl, Azcón R, Ruiz-Lozano JM, Aroca R (2019) Rhizobial symbiosis modifies root hydraulic properties in bean plants under non-stressed and salinitystressed conditions. Planta 249(4):1207-1215

Fu G, Feng B, Zhang C, Yang Y, Yang X, Chen T, Zhao X, Zhang X, Jin Q, Tao L (2016) Heat stress is more damaging to superior spikelets than inferiors of rice (Oryza sativa L.) due to their different organ temperatures. Front. Plant Sci 7:1637

Gong M, Li YJ, Chen SZ (1998) Abscisic acid-induced thermotolerance in maize seedlings is mediated by calcium and associated with antioxidant systems. J Plant Physiol 153(3-4):488-496

Grenert JP, Sullivan WP, Fadden P, Haystead TA, Clark J, Mimnaugh E, Krutzsch H, Ochel HJ, Schulte TW, Sausville E, Neckers LM, Toft DO (1997) The aminoterminal domain of heat shock protein 90 (hsp90) that binds geldanamycin is an ATP/ADP switch domain that regulates hsp90 conformation. J Biol Chem 272(38):23843-23850

Grover A, Mittal D, Negi M, Lavania D (2013) Generating high temperature tolerant transgenic plants: achievements and challenges. Plant Sci 205-206: 38-47

Guajardo E, Correa JA, Contreras-Porcia L (2016) Role of abscisic acid (ABA) in activating antioxidant tolerance responses to desiccation stress in intertidal seaweed species. Planta 243(3):767-781

Hu XJ, Chen D, Lynne McIntyre C, Fernanda Dreccer M, Zhang ZB, Drenth J, Kalaipandian S, Chang H, Xue GP (2018) Heat shock factor C2a serves as a proactive mechanism for heat protection in developing grains in wheat via an ABA-mediated regulatory pathway. Plant Cell Environ 41(1):79-98

Huang Y, Sun MM, Ye Q, Wu XQ, Wu WH, Chen YF (2017) Abscisic acid modulates seed germination via ABA INSENSITIVE5-mediated PHOSPHATE1. Plant Physiol 175(4):1661-1668

Islam MR, Feng B, Chen T, Fu W, Zhang C, Tao L, Fu G (2019) Abscisic acid prevents pollen abortion under high-temperature stress by mediating sugar metabolism in rice spikelets. Physiol Plant 165(3):644-663

Islam MR, Feng B, Chen T, Tao L, Fu G (20De Block18) Role of abscisic acid in thermal acclimation of plants. J Plant Biol 61(5):255-264

Israel D, Khan S, Warren CR, Zwiazek JJ, Robson TM (2019) Contribution of PIP2 aquaporins to photosynthesis in response to increased vapour pressure deficit. Plant Physiol. https://doi.org/10.1101/847053

Jacob P, Hirt H, Bendahmane A (2017) The heat-shock protein/chaperone network and multiple stress resistance. Plant Biotechnol J 15(4):405-414

Jahan A, Komatsu K, Wakida-Sekiya M, Hiraide M, Tanaka K, Ohtake R, Umezawa T, Toriyama T, Shinozawa A, Yotsui I, Sakata Y, Takezawa D (2019) Archetypal roles of an abscisic acid receptor in drought and sugar responses in liverworts. Plant Physiol 179(1):317-328

Kaldenhoff R, Ribas-Carbo M, Sans JF, Lovisolo C, Heckwolf M, Uehlein N (2008) Aquaporins and plant water balance. Plant Cell Environ 31(5):658-666

Kang M, Lee S, Abdelmageed H, Reichert A, Lee HK, Fokar M, Mysore KS, Allen RD (2017) Arabidopsis stress associated protein 9 mediates biotic and abiotic stress responsive $A B A$ signaling via the proteasome pathway. Plant Cell Environ 40(5):702-716

Kumar S, Kaushal N, Nayyar H, Gaur P (2012) Abscisic acid induces heat tolerance in chickpea (Cicer arietinum L.) seedlings by facilitated accumulation of osmoprotectants. Acta Physiol Plant 34(5):1651-1658

Li H, Liu SS, Yi CY, Wang F, Zhou J, Xia XJ, Shi K, Zhou YH, Yu JQ (2014) Hydrogen peroxide mediates abscisic acid-induced hsp70 accumulation and 
heat tolerance in grafted cucumber plants. Plant Cell Environ 37(12):27682780

Li L, Shi ZY, Li L, Shen GZ, Wang XQ, AnLS ZJL (2010) Overexpression of acl1 (abaxially curled leaf 1) increased bulliform cells and induced abaxial curling of leaf blades in rice. Mol Plant 3(5):807-817

Li XM, Chao DY, WU Y, Huang XH, Chen K, Cui LG, Su L, Ye WW, Chen H, Chen HC, Dong NQ, Guo T, Shi M, Feng Q, Zhang P, Han B, Shan JX, Gao JP, Lin HX (2015) Natural alleles of a proteasome a2 subunit gene contribute to thermotolerance and adaptation of African rice. Nat Genet 47:827-833

Liu Y, Offler CE, Ruan YL (2016) Cell wall invertase promotes fruit set under heat stress by suppressing ROS-independent plant cell death. Plant Physiol 172(1): 163-180

Matsumura H, Miyachi S (1983) In: San Pietro A (ed) Methods in enzymology, vol 69. Academic Press, New York, pp 465-470

Maurel C, Verdoucq L, Rodrigues O (2016) Aquaporins and plant transpiration. Plant Cell Environ 39(11):2580-2587

McGaughey SA, Qiu J, Tyerman SD, Byrt CS (2018) Regulating root aquaporin function in response to changes in salinity. Annu Plant Rev. https://doi.org/ 10.1002/9781119312994.apr0626

Mittler R, Blumwald E (2015) The roles of ROS and ABA in systemic acquired acclimation. Plant Cell 27(1):64-70

Moshelion M, Halperin O, Wallach R, Oren R, Way DA (2015) Role of aquaporins in determining transpiration and photosynthesis in water-stressed plants: crop water-use efficiency, growth and yield. Plant Cell Environ 38(9):17851793

OToole JC, Cruz RT (1980) Response of leaf water potential, stomatal resistance, and leaf rolling to water stress. Plant Physiol 65(3):428-432

Poudyal D, Rosenqvist E, Ottosen CO (2019) Phenotyping from lab to fieldtomato lines screened for heat stress using Fv/Fm maintain high fruit yield during thermal stress in the field. Funct Plant Biol 46(1):44-55

Quiroga G, Erice G, Ding L, Chaumont F, Aroca R, Ruiz-Lozano JM (2019) The arbuscular mycorrhizal symbiosis regulates aquaporins activity and improves root cell water permeability in maize plants subjected to water stress. Plant Cell Environ 42(7):2274-2290

Rissel D, Heym PP, Thor K, Brandt W, Wessjohann LA, Peiter E (2017) No silver bullet-canonical poly (ADP-ribose) polymerases (PARPs) are no universal factors of abiotic and biotic stress resistance of Arabidopsis thaliana. Front Plant Sci 8:59

Robertson AJ, Ishikawa M, Gusta LV, MacKenzie SL (1994) Abscisic acid-induced heat tolerance in bromus inermis leyss cell-suspension cultures. Heat-stable, abscisic acid-responsive polypeptides in combination with sucrose confer enhanced thermostability. Plant Physiol 105(1):181-190

Rozen S, Skaletsky H (2000) Primer3 on the WWW for general users and for biologist programmers. In: Misener S, Krawetz SA (eds) Bioinformatics methods and protocols. Methods in molecular biology ${ }^{\mathrm{TM}}$, vol 132. Humana Press, Totowa

Rubio S, Noriega X, Pérez FJ (2018) Abscisic acid (ABA) and low temperatures synergistically increase the expression of CBF/DREB1 transcription factors and cold-hardiness in grapevine dormant buds. Ann Bot 20:1-9

Rytz TC, Miller MJ, McLoughlin F, Augustine RC, Marshall RS, Juan YT, Charng YY, Scalf M, Smith LM, Vierstra RD (2018) SUMOylome profiling reveals a diverse array of nuclear targets modified by the SUMO ligase SIZ1 during heat stress. Plant Cell 30(5):1077-1099

Sarieva GE, Kenzhebaeva SS, Lichtenthaler HK (2010) Adaptation potential of photosynthesis in wheat cultivars with a capability of leaf rolling under high temperature conditions. Russ J Plant Physl 57(1):28-36

Sartory DP, Grobbelaar JU (1984) Extraction of chlorophyll a from freshwater phytoplankton for spectrophotometric analysis. Hydrobiologia 114(3):177187

Sehgal A, Sita K, Bhandari K, Kumar S, Kumar J, Vara Prasad PV, Siddique KHM, Nayyar H (2019) Influence of drought and heat stress, applied independently or in combination during seed development, on qualitative and quantitative aspects of seeds of lentil (Lens culinaris Medikus) genotypes, differing in drought sensitivity. Plant Cell Environ 42(1):198-211

Shen H, Zhong X, Zhao F, Wang Y, Yan B, Li Q, Chen G, Mao B, Wang J, Li Y, Xiao G, He Y, Xaio H, Li J, He Z (2015) Overexpression of receptor-like kinase ERECTA improves thermotolerance in rice and tomato. Nat Biotechnol 33: 996-1003

Suzuki N, Bassil E, Hamilton JS, Inupakutika MA, Zandalinas SI, Tripathy D, Luo Y, Dion E, Fukui G, Kumazaki A, Nakano R, Rivero RM, Verbeck GF, Azad RK,
Blumwald E, Mittler R (2016) ABA is required for plant acclimation to a combination of salt and heat stress. PLoS One 11(1):e0147625

Tiwari BS, Belenghi B, Levine A (2002) Oxidative stress increased respiration and generation of reactive oxygen species, resulting in ATP depletion, opening of mitochondrial permeability transition, and programmed cell death. Plant Physiol 128(4):1271-1281

Vanderauwera S, De Block M, Van de Steene N, Van De Cotte B, Metzlaff M, Van Breusegem F (2007) Silencing of poly (ADP-ribose) polymerase in plants alters abiotic stress signal transduction. P Natl Acad Sci USA 104(38):1515015155

Verslues PE, Zhu JK (2007) New developments in abscisic acid perception and metabolism. Curr Opin Plant Biol 10(5):447-452

Wahid A, Gelani S, Ashraf M, Foolad MR (2007) Heat tolerance in plants: an overview. Environ Exp Bot 61(3):199-223

Wang Y, Chang H, Hu S, Lu X, Yuan C, Zhang C, Wang P, Xiao W, Xiao L, Xue GP, Guo X (2014) Plastid casein kinase2 knockout reduces abscisic acid (ABA) sensitivity, thermotolerance, and expression of ABA-and heat-stressresponsive nuclear genes. J Exp Bot 65(15):4159-4175

Wu C, Cui K, Hu Q, Wang W, Nie L, Huang J, Peng S (2019) Enclosed stigma contributes to higher spikelet fertility for rice (Oryza sativa L.) subjected to heat stress. Crop J 7(3):335-349

Wu Q, Hu Y, Sprague SA, Kakeshpour T, Park J, Nakata PA, Cheng N, Hirschi KD, White FF, Park S (2017) Expression of a monothiol glutaredoxin, AtGRXS17, in tomato (solanum lycopersicum) enhances drought tolerance. Biochem Bioph Res Co 491(4):1034-1039

Xie K, Li L, Zhang H, Wang R, Tan X, He Y, Hong G, Li J, Ming F, Yao X, Yan F, Sun Z, Chen J (2018) Abscisic acid negatively modulates plant defence against rice black-streaked dwarf virus infection by suppressing the jasmonate pathway and regulating reactive oxygen species levels in rice. Plant Cell Environ 41(10):2504-2514

Xiong J, Zhang L, Fu G, Yang Y, Zhu C, Tao L (2012) Drought-induced proline accumulation is uninvolved with increased nitric oxide, which alleviates drought stress by decreasing transpiration in rice. J Plant Res 125(1):155-164

Yang J, Zhang J, Wang Z, Zhu Q, Wei W (2001) Hormonal changes in the grains of rice subjected to water stress during grain filling. Plant Physiol 127(1):315323

Yao L, Cheng X, Gu Z, Huang W, Li S, Wang L, Wang YF, Xu P, Ma H, Ge X (2018) The AWPM-19 family protein OsPM1 mediates abscisic acid influx and drought response in rice. Plant Cell 30(6):1258-1276

Zandalinas SI, Balfagón D, Arbona V, Gómez-Cadenas A, Inupakutika MA, Mittler R (2016) ABA is required for the accumulation of APX1 and MBF1c during a combination of water deficit and heat stress. J Exp Bot 67(18):5381-5390

Zandalinas SI, Mittler R, Balfagón D, Arbona V, Gómez-Cadenas A (2018) Plant adaptations to the combination of drought and high temperatures. Physiol Plant 162(1):2-12

Zhang CX, Feng BH, Chen TT, Fu WM, Li HB, Li GY, Jin QY, Tao LX, Fu GF (2018) Heat stress-reduced kernel weight in rice at anthesis is associated with impaired source-sink relationship and sugars allocation. Environ Exp Bot 155: 718-733

Zhang CX, Fu GF, Yang XQ, Yang YJ, Zhao X, Chen TT, Zhang XF, Jin QY, Tao LX (2016) Heat stress effects are stronger on spikelets than on flag leaves in rice due to differences in dissipation capacity. J Agron Crop Sci 202(5):394-408

Zhang J, Shi Y, Zhang X, Du H, Xu B, Huang B (2017) Melatonin suppression of heat-induced leaf senescence involves changes in abscisic acid and cytokinin biosynthesis and signaling pathways in perennial ryegrass (Loliumperenne L. ). Environ Exp Bot 138:36-45

Zhang S, Feng M, Chen W, Zhou X, Lu J, Wang Y, Li Y, Jiang CZ, Gan SS, Ma N, Gao I (2019) In rose, transcription factor PTM balances growth and drought survival via PIP2;1 aquaporin. Nat Plants 5:290-299

Zhang YJ (1977) Determination of glucose, fructose, sucrose and starch in fruit and vegetable with anthrone colorimetric method. Chin J Anal Chem 5(3): $167-171$

Zhu JK (2016) Abiotic stress signaling and responses in plants. Cell 167(2):313324

\section{Publisher's Note}

Springer Nature remains neutral with regard to jurisdictional claims in published maps and institutional affiliations. 